\title{
Platform development: implications for portfolio management
}

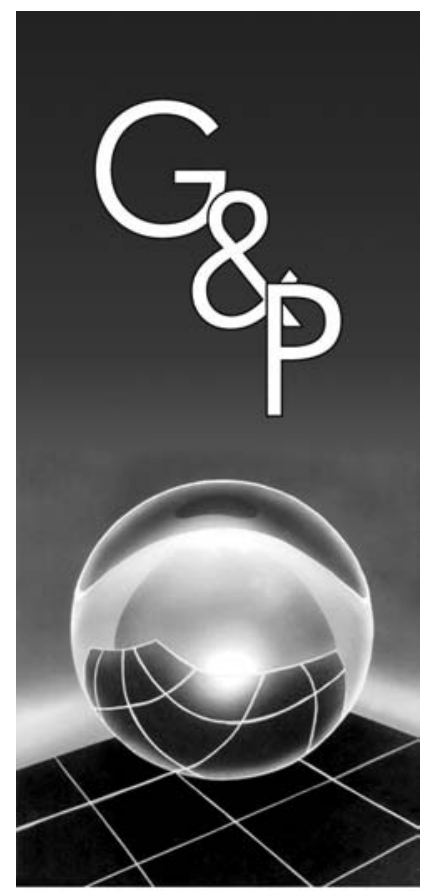

\author{
Juliana Hsuan \\ Poul Kyvsgaard Hansen
}

\begin{abstract}
The challenge of implementing industrial platforms in practice can be described as a configuration problem caused by a considerable number of variables, which often have contradictory influences on the total performance of the firm. Consequently, the specific platform decisions become extremely complex, possibly increasing the strategic risks for the firm. This paper reports preliminary findings on platform management process at LEGO, a Danish toy company. Specifically, we report the process of applying games combined with simulations and workshops in the platform development. We also propose a framework, based on the portfolio management thinking to evaluate the degree of modularity embedded in a given platform and to which extent it is aligned with other platforms.
\end{abstract}

Keywords: Platform. Portfolio management. Case study.

INVITED PAPER

\section{Introduction}

Platform is a concept that involves various theoretical perspectives (i.e. organization, innovation, supply chain management, economics, etc.). Although the philosophy behind platforms and platform thinking is easy to communicate and makes intuitive sense, its implementation can be extremely challenging due to its inhered complexity. The challenge of implementing industrial platforms can be described as a configuration problem caused by a considerable number of variables. These variables are different in nature; each one has its own influence on the total performance positively or negatively.

One particular problem is to foresee qualitative and quantitative effects of the platform effort. Initially, some companies accept qualitative arguments, so the platform implementation effort can be started. However, as the company gain experience, requirements for both qualitative and quantitative methods become necessary. Since platform initiatives affect cross-organizational units and financial periods, the challenges related to organizing and communicating these initiatives become highly complex.

Some companies have developed or adapted simulation systems to visualize and communicate effects. However, these systems tend to be specialized tools which create complexities of their own. Recently, a new approach has drawn some attention: games. An increasing number of companies are developing games to facilitate training for decision making in complex settings. One of the promising new methods is the application of on-line games in order to provide training for decision makers and to generate an overview of the implications of platform decisions. However, games have to be placed in a context with other methods, we argue that a mixture of games, workshops, and simulations can provide improved support for the platform decision making.

In order to capture the complexity of the platform realization process, which varies from firm to firm, this paper describes how LEGO deals with this issue. This paper is organized as follows. Firstly, theoretical foundation about platform management is presented. Then, our research methodology (i.e. action research and case study research) is explained. Next, the LEGO case is presented. Finally, we propose the Platform Portfolio Matrix, as a tool to measure the degree of the modularity embedded in a platform with respect to the extent to which it is aligned with other platforms. 


\section{Theoretical foundation}

The theoretical foundation of the paper is derived from the literature on platforms and products (e.g., MEYER; LEHNERD, 1997; MIKKOLA, 2006; MUFFATTO; ROVEDA, 2000; CUSUMANO; GAWER, 2002), the implementation of complex decisions, our prior experiences with virtual design team (VDT) simulation tool (MABOGUNJE et al., 1995; HANSEN et al., 1997), and a newly initiated EU-project (PRIME, providing real integration in multi-disciplinary environments).

\subsection{Platform management}

Platform as a management concept is not new. In his reflections upon the setup at Ford Motor Company, Henry Ford made a description of the careful delineation of subsystems inside an automobile and examined new component technologies both inside and outside the company to improve comfort, ease of use, and durability (FORD, 1988). As stated in the introduction this makes intuitive sense, but due to its great complexity, it is extremely challenging to implement a platform strategy in an effective and efficient way. The complexity refers to the structural complexity of the platform variables as well as the complexity of implementing organization and the complexity that arises from the dynamic change in technology and markets.

The challenges of managing platforms fit well with the challenges defined within the area of "general systems theory." Herbert Simon (1996) defines complexity as the main problem of handling systems:

\footnotetext{
"Roughly, by a complex system I mean one made up of a large number of parts that interacts in a non-simple way. In such systems the whole is more than the sum of the parts, not in an ultimate, metaphysical sense but in the important pragmatic sense that, given the properties of the parts and the laws of their interaction, it is not a trivial mater to infer the properties of the whole."
}

When we explore this way of thinking to the best known and the most often cited platform - the A-platform of Volkswagen (Figure 1) - we often view the platform as the physical and structural unit including the suspension, rear axel, brakes, engine, gearbox, etc. However, it might be relevant to remember the painting of a pipe by the Belgian painter, René Magritte. Magritte named the picture "Cesi n'est pas une pipe!" - It is not a pipe; it is a model of a pipe!

The physical representation of the Volkswagen A-platform is not a platform. It is a rather simple, visual representation of a number of structural subsystems. Furthermore, we evade the most important issue: the associated supply chain systems or at least their inter-

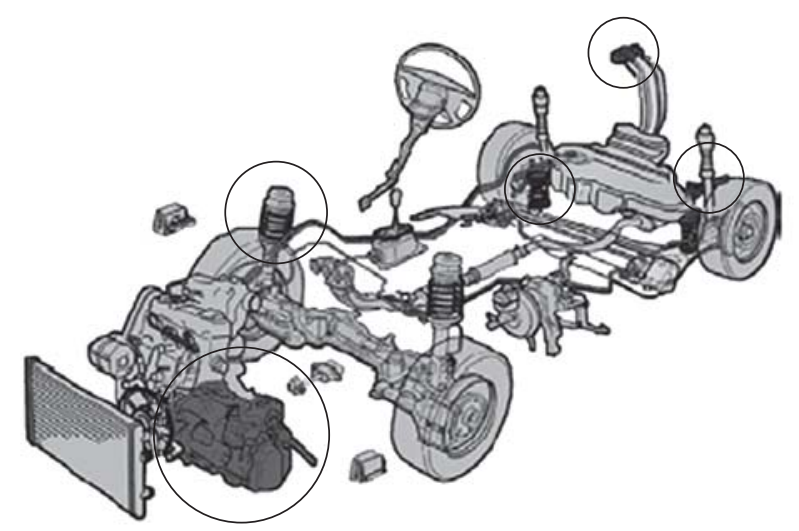

Figure 1. This is not a platform!

faces to the product subsystems. These subsystems and their interfaces are the explanation for the specific physical form, and most importantly are the reasons why Volkswagen has been able to gain from both product development and their supply chains.

The effects are determined by a non-simple interaction between various multidisciplinary sub-systems. To select and configure these subsystems and their interaction is, in short, the management challenge of working with platforms. Due to differences in market dynamics, technology platforms tend to be different from company to company. Consequently, there is a need to provide a rich and comprehensive view of platform options to support the company specific work with platforms. We have termed this a platform template. In order to investigate how a platform template can be defined, we have separated the platform management into three levels of analysis (Figure 2): firm, supply chain, and industry. Overall, the platform implementation challenge has two independent but highly interrelated perspectives: i) a structural perspective that includes the company specific selection and configuration of the particular platform variables to be included; and ii) a process perspective that includes the organizational aspects of the implementation. Both the structural and the process perspectives pose a vast number of challenges to industry and academia as well.

\subsubsection{Platform at the firm level}

A great deal of literature on platform has been studied at the firm level, notably in terms of product platform. The most widely used definition of product platform is the one provided by Meyer and Lehnerd (1997, p. 39):

"product platform is a set of subsystems and interfaces that form a common structure from which a stream of derivative products can be efficiently developed and produced."

This definition has been extended to provide a focus on shared assets (cf. KRISHNAN; GUPTA, 2001; 


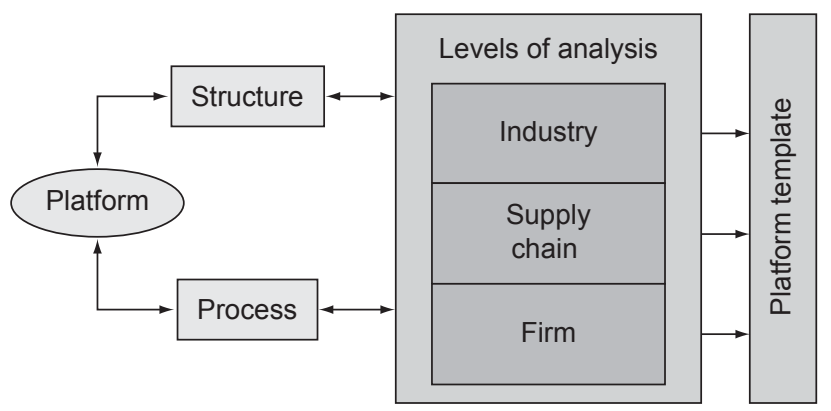

Figure 2. Research framework for defining the platform template.

ROBERTSON; ULRICH, 1998). For instance, Robertson and Ulrich (1998) define product platform as a collection of shared assets (such as components, processes, knowledge, and people and relationships) that are shared among a set of products.

As Robertson and Ulrich (1995, p. 29) articulate, "making good platform decisions requires making complex trade-offs in different business areas. Top management should play a strong role in the platform process for three reasons: i) platform decisions are among the most important ones a company makes; ii) platform decisions may cut across several product lines or divisional boundaries; and iii) platform decisions frequently require the resolution of cross-functional conflict."

There are several reasons why firms pursue a product platform strategy. Some of the benefits of product platforms include the reduction in the fixed costs of developing individual product variants, greater degree of components and subsystems reuse, increased firms' responsiveness, larger product variety offered to customers, reduction of development lead time, and improved customer service. However, the implementation of a product platform can also be extremely challenging due to the coordination problems that may arise from too much product variety. Customer needs may actually be more difficult to be articulated than expected. The organization itself might exert resistance if the balance between distinctiveness and commonality can not be leveraged to fit the capabilities of the organization.

In order to implement a platform strategy, product architecture strategies (which can range from modular to integral) have to be devised. The purpose of devising modular product architecture designs is to create flexibility and changeability (ERENS; VERHULST, 1997). Product architecture can be defined as the arrangement of the functional elements of a product into several building blocks, including the mapping from functional elements to physical components and the specification of the interfaces among interacting physical components (ULRICH; EPPINGER, 2004). At the heart of the platform is the organization of components and interfaces making up the product architecture. The degree of modularity embedded in the product architectures is dependent on the composition of the components, how these components are linked with one another, and the substitutability of unique components (MIKKOLA; GASSMANN, 2003).

\subsubsection{Platform at the supply chain level}

Platform management at the supply chain level often focuses on how a product family and related derivative products are determined by the decisions related to product design, manufacturing processes, and sourcing. Muffatto and Roveda (2000), for instance, identify four concepts that affect product platform strategy: i) production and logistics processes; ii) development processes; iii) project organizational structure; and iv) knowledge. Various scholars have also linked product platform to the trade-offs between distinctiveness and commonality (cf. MUFFATTO; ROVEDA, 2000; ROBERTSON; ULRICH, 1998; FARRELL; SIMPSON, 2003). Distinctiveness is related to the degree to which a firm is capable of producing products that are differentiable from competitors' products, which is then related to the amount of uniqueness that is idiosyncratic to a particular platform. Commonality, on the other hand, deals with the extent to which components or subsystems are shared or reused across platforms in order to create economies of scale and product variety. Here, the standardization of interfaces (whether processes or components) becomes a central issue of concern. The trade-offs between distinctiveness and commonality are one of the challenges that management face during the platform planning process.

The trade-offs between distinctiveness and commonality are further influenced by the degree of product customization offered to the customers. Mass customization and postponement strategies, for instance, are closely linked to modularization strategies in terms of task decomposition, extent of mixing-and-matching, and degree of supplier-buyer interdependence (MIKKOLA; SKJØTTLARSEN, 2004). While the goal of mass customization is to provide products that meet customers' individual needs through unique combinations of modular components (PINE, 1993), postponement is about delaying the timing of crucial processes in which end products assume their specific functionalities, features, and identities (LEE, 1998).

\subsubsection{Platform at the industry level}

As explained by Meyer and Dalal (2002, p. 278), platform management is "the integration of the building blocks (the core technologies and processes) with common architectures (the shared subsystems and interfaces), with user requirements aggregated into target market segments towards the end of producing value rich products and systems." Product platform has tremendous 
implications for a firm's product portfolio management, in which a set of technologies and products are evaluated in relation to one another (MIKKOLA, 2001). How a platform is planned and configured, in terms of the technology composition contained in the sub-systems and respective interfaces linking these sub-systems, has a significant impact on the trade-offs between the degree of standardization and customization of product families and respective end products. The result of that integration should be the product families that serve a spectrum of price and performance for one or more market segments. Furthermore, having a platform leadership (CUSUMANO; GAWER, 2002) allows a company to develop innovation of a particular platform technology at the broad industry level. Platform leaders, however, face three problems:

a) how to maintain the integrity of the platform (the compatibility with complementary products) in the face of future technological innovation and the independent product strategies of other companies;

b) how to let platforms evolve technologically while maintaining compatibility with past complements; and

c) how to maintain platform leadership.

\subsection{Learning by gaming}

Learning and decision making, through games for instance, are two closely related concepts, but extremely difficult to be implemented in organizations. In order to learn, organizations need to create the right culture for learning, have sufficient time, and provide tools to facilitate learning. Learning is also embedded in our cultural heritage, which means that organizations need to create a setup where "what is" and "what we used to do" can be questioned, and "what could be" and "why don't we" can be encouraged and facilitated.

Although the general approach to learning is the traditional classroom setting, this is a valid method for teaching novices only. To help professionals learn we need to introduce interactive methods that support experimentation and reflection (KOLB, 1984; SCHÖN, 1983). In professional settings, learning takes place in relation to a specific environment. When managers learn, they get a better understanding of this environment; they can improve their ability to adapt to the environment or to change the environment. In our project, the learning process is conceptualized to fit into three categories, as shown in Figure 3: Workshops, Simulations, and Games. These three categories mean having different goals. When they are applied in the specific environment, each one stimulates the various elements of the learning process differently.

WORKSHOP: Generally the workshop category is defined as: "An educational seminar or series of meetings

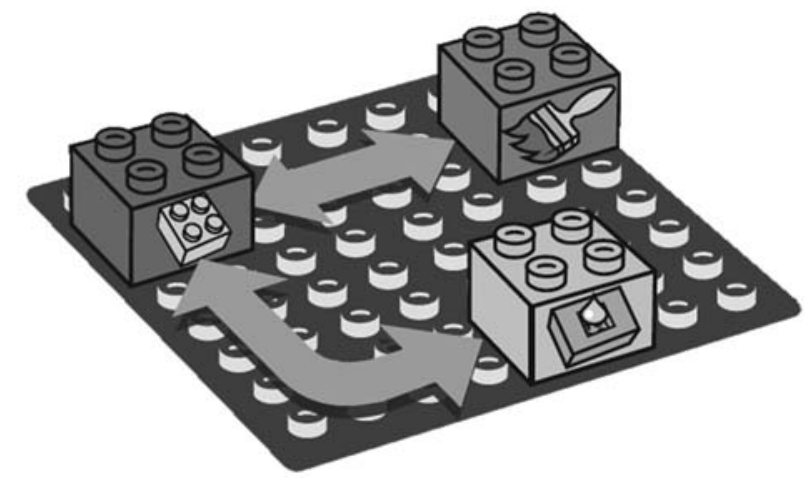

Figure 3. A conceptual model of the learning practice.

emphasizing interaction and information exchanging among a, usually, small number of participants." The workshop element is the social engagement element. In this sense, workshops are required for any learning process. Simple problems can normally be handled by a workshop alone, such as when a few people gather to solve or to communicate an experienced problem. As problems become more complex the power of social workshops decreases. That is, when the number of variables increases, the capacity of the human brain to handle new information reaches a limit. People often choose one of the following strategies: do what they have done before or negotiate a compromise which may not be optimal. Both strategies are conservative in terms of learning, and they might not provide the desired solution to the problem under investigation.

SIMULATION: Simulation is generally understood in the context of mathematical simulation. The encyclopedia describes simulation in the following way: "A simulation is an imitation of some real thing, state of affairs, or process. The act of simulating something generally entails representing certain key characteristics or behaviors of a selected physical or abstract system. Simulation is used in many contexts including the modeling of natural systems or human systems in order to gain insight into their functioning. Other contexts include simulation of technology for performance optimization, safety engineering, testing, training, and education. Simulation can be used to show the eventual effects of alternative conditions and courses of action. Key issues in simulation include acquisition of valid source of information about the referent, selection of key characteristics and behaviors, the use of simplifying approximations and assumptions within the simulation, and fidelity and validity of the simulation outcomes."

GAMES: In Got Game, a book published in 2004 by Harvard Business School Press, John Beck and Mitchell Wade argue that gaming provides excellent training for professionals in business. According to them, gamers are skilled at multi-tasking, good at making decisions and 
evaluating risks, flexible in dealing with changes, and inclined to treat setbacks as chances to try again.

New approaches emerge when the new opportunities, provided by games, are combined with the traditional opportunities of simulation and targeted workshops. While games give us opportunities for social play, simulations provide opportunities for conceptual play, enabling the testing of new ideas and theories. For instance, simulations allow one to test evolutionary properties of a system over a thousand cycles (or as many cycles as one wishes). While simulations and games are experiential with respect to present or future situations, workshops are discursive. They involve interactions amongst stakeholders that involve the clarification of situations, generation of alternatives, handling of ambiguities, and reflection on actions previously taken (SCHRAGE, 2000).

\section{Research methodology}

As mentioned earlier, although the platform development process includes two different aspects (i.e. process and structure), it is important to view and manage them as a whole. There are almost no studies available (at least not to the authors' knowledge) that reveal statistically significant cause-effect relationships regarding platforms. We interpret this as a consequence of three factors:

a) the complexity of the cross-organizational platform efforts;

b) the differences between companies and industries there are no standard solutions; and

c) the maturity of the research within the field - platform management is an emerging topic.

Consequently, we have chosen to conduct our empirical investigation as case studies. According to Yin (1994), a case study is an advantageous strategy when 'how' and 'why' questions are being asked about a contemporary set of events, over which the investigator has little or no control. Due to the complexity of the phenomena under investigation, we have also setup major parts of the empirical research by applying the action research approach. Our definition of action research is provided by Gummersson (2000) as "the combination of research and management consultancy that involves interventions into processes of decision making, implementation, and change."

An intensive case study has been conducted with the LEGO Group, which was complemented with an action research project aiming at observing, documenting, and impacting the related work platform at the company. For four years (from 2002 to 2006), one of the authors spent from two to three days per week at the company. Concurrently, academic literature was reviewed and more than 20 case studies were conducted with the participation of four action research projects. One of the results of this study was the identification of eight factors or potential elements of the platform management, which we call 'platform template' (MIKKOLA; HANSEN, 2005). These factors are:

a) the platform is based on one or more architectures;

b) it forms a meaningful part of a product or process;

c) it includes relevant knowledge at the architectural level;

d) it serves as a basis for long-term development work;

e) it serves as a basis for short and medium-term continuous improvement;

f) it is based on a partly modular structure (by adopting modular architectures);

g) it specifies internal and external interfaces; and

h) it is specific about where to gain effects.

\section{Case study: Lego group}

LEGO is a Danish toy company, founded in 1932, which is globally known for its bricks that snap together to form a structure. Since its beginning, the company has grown from producing only a small variety of LEGO bricks to a large array of different bricks. For instance, it added the DUPLO ${ }^{\circledR}$ bricks for smaller kids, and the TECHNIC $^{\circledR}$ range, which allows mechanical assemblies including gears and motors. More recently LEGO has introduced the MINDSTORMS ${ }^{\circledR}$ range, which includes a computer, infrared transmitter and a receiver, and software and sensors as well as the motors and bricks of the earlier products. Users can now make relatively sophisticated robots with sensors that can receive sets of instructions through robot programming language (HANSEN; MIKKOLA, 2004).

In 2001, LEGO felt an urgent need to reshape their strategy on how platforms were being applied and understood. They were facing a situation in which the term 'platform' was used in many different meanings, and it seemed that there were a large number of platforms. There were platforms for the building systems (DUPLO ${ }^{\circledR}$, TECHNIC $^{\circledR}$, SYSTEM $^{\circledR}$, etc.), platforms for electronic technologies, platforms for different types of moulds, platforms for various kinds of decoration equipment, platforms for many types of materials, platforms for the packaging equipment, and platforms for packing solutions. In order to tackle this problem, the whole process had to be reorganized. In short, LEGO decided that what was originally viewed as platforms should then be viewed as architectures (O'GRADY, 1999; HANSEN; MIKKOLA, 2004). The new platforms would emerge as a number of aligned architectures. This process led to a more consistent understanding and definition.

Figure 4 illustrates a simple platform with a building system as the key element which is aligned with mould 


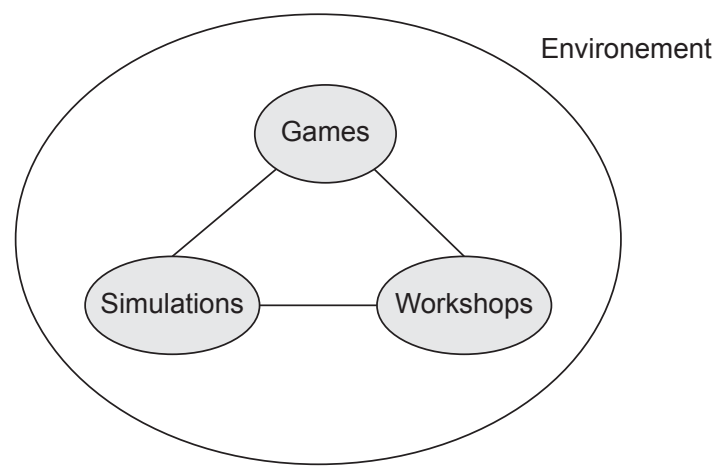

Figure 4. The illustrative figure used to communicate the platform understanding at LEGO.

architecture and decoration architecture. As a consequence the number of platforms was reduced to the same number of building systems. The most important platforms are the DUPLO ${ }^{\circledR}$ platform, the SYSTEM $^{\circledR}$ platform, and the TECHNIC ${ }^{\circledR}$ platform (see http://www.lego. com for further details).

The platform development process is consisted of two different tasks: i) to update the current architectures according to the market requirements; and ii) to make sure that the updated architectures in the platform are sufficiently aligned, and that the alignments of existing architectures are continuously improved. The following three situations illustrate the challenge of these tasks:

The marketing department was asking for special bricks in order to differentiate the products. These special bricks were typically produced in smaller numbers and consequently modifying the existing mould architectures was considered too expensive. Hence, new mould architecture was developed - a very different architecture from the existing one. The new mould architecture included an industrial-produced mould frame and a flexible setup to produce the core element of the mould. Since the process was radically different from the existing mould production process, a whole new process had to be developed. The new mould architecture had some limitations in terms of geometrical possibilities for snapping the bricks. These limitations had to be communicated efficiently to the designers. All of these adjustment activities characterize the content of the alignment process.

The dominant decoration technique is the pad-printing process, a low cost technique when the batch size is high. However, this technique is rather inflexible when the batch size is low. Therefore, the team frequently has to consider whether new digital decoration techniques are available. Yet, the alternatives have not proven to be cost-competitive, mainly because the existing setup is efficiently aligned with the existing supply chain process and the designer. A change would initiate a cascade of changes in the whole setup.
In 2003, it was decided to redesign the DUPLO characters. Marketing was requesting a more organic and appealing design. The redesign required a thorough alignment with mould, decoration, and assembly architectures. The group had to consider whether parts of the original product elements and the supply chain setup could be reused. Although all parts of the product were redesigned, significant parts of the supply chain were reused. The final design of the DUPLO character is illustrated in Figure 5.

Those three examples illustrate how challenging aligning architectures can be. It is clear that the judgment about the efficiency and effectiveness of the quality of the alignment is not an either-or binary question. It is a complex cross-organizational and inter-organizational problem where it is difficult to get the full overview of the consequences. This is one of the motivations to develop games with which various situations can be played.

\section{Gaming for platform management}

New insights into how games can be used in professional settings have triggered a variety of efforts to develop games for this particular purpose. Our current project is a part of PRIME, an EU-funded project. The main objective of the PRIME project is to provide business professionals with a learning environment where they can experiment with new ideas and learn how to handle the entire life cycle of products and processes for all stakeholders of the organization. PRIME proposes to achieve this by enhancing current work environments with a new paradigm based on serious gaming. This should provide the means for learning by experience within a virtual environment that is safe. It should also allow room for risk taking without forging into detrimental impact on the business.

Our long-term relationship with LEGO has provided us with an opportunity to base the test cases on real data and real products. Furthermore, the games can be tested with real decision makers. The focus of our project, so far, has been on the launch process of new products. Each year approximately 20 new products are launched counting for more than $50 \%$ of the sales. However, the products rarely sell according to the initial budgets. While some products sell for four times as much as the budgeted plan, others sell for significantly less.

When operating in a highly competitive environment, such as the case of the traditional toy market, there are obviously several challenges related to this launch process. In this paper, we have chosen to focus on two overall challenges.

The first challenge is concerned with the approval of the concepts. During the concept development phase, the concepts change frequently due to new inputs regarding 


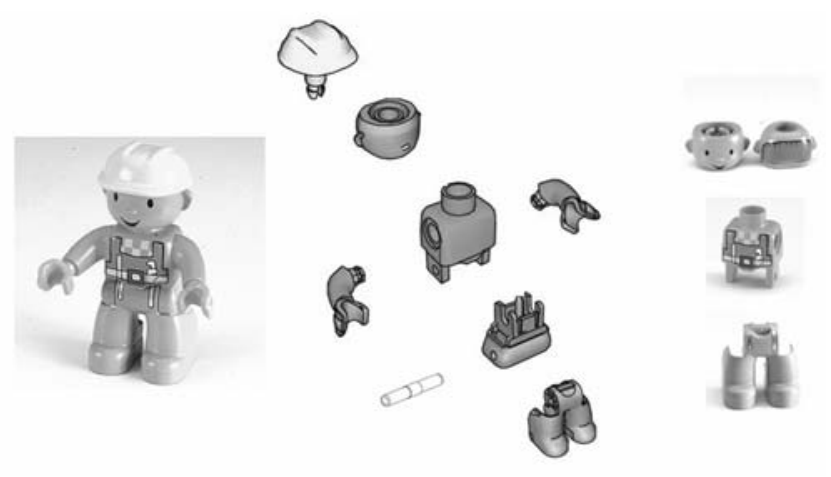

Figure 5. The DUPLO character and the product structure.

competitors and technological possibilities. Only during the last weeks before approval, the concepts converge into their final presentation. During this process, the participants from different market segments are usually more focused on their own concepts. This means that the concepts in the portfolio are not aligned. Seen from the individual concept's perspective this leads to concepts without compromises. Seen from the perspective of the whole organization, this can easily lead to sub-optimizations. This challenge is interpreted as the degree of platform application across the whole portfolio.

The second challenge is concerned with the manufacturing setup. As the last part of the product development phase, the manufacturing unit has to adapt to engineering and to be flexible to changes in the market. This is facilitated by establishing flexible manufacturing platforms both within the company and in collaboration with suppliers. The efficiency of these manufacturing platforms is highly dependent on the specific product portfolio. When problems of delivery or quality occur later in the process, it has become easier to identify these problems based on the chosen product portfolio.

Both challenges are, to a great extent, related to the decision on the specific product portfolio and the decisions regarding platform development. The evaluation of the consequences requires a substantial cross-organizational effort. There is a great amount of knowledge about such effects spread across the organization, but it is often a tacit agreement or there are unclear cause-effect relationships. If the consequences of a specific choice of product portfolio can be revealed, it is normally possible to change elements of the portfolio without weakening the marketing ideas put forward. But since the consequences are not easily revealed and the number of variables is high, it is not at all clear where to intervene.

\section{Portfolio management of platforms}

The critical questions when applying a platform in a product development process relate mostly to communi- cation, existence of portfolios, and timing issues. Good platform communication is a company specific problem as it has to match the current challenges in the particular industry with the organizational structure of the company. This means that the platform communication challenge varies from company to company.

The existence of portfolios of products (and respective supply chains) raises a challenge for a firm especially across different product programs. Reusing a component from another product platform, for instance, might be motivated by the possibilities of gains from economies of scale in production. This is complicated further and often by the fact that the reuse might take place within a time span of several years. The logic of reusing is that a single component often gets more costly. Most financial systems are not able to capture the benefits from such kinds of reuse.

Timing is also crucial. Additional resources often have to be added when a component with reuse potential is developed, which means longer development time. Development teams are often caught in a dilemma between developing their own solutions and waiting for a solution from a decoupled platform team. In addition, the old saying applies: "The devil is in the details" - the reason why a particular solution fails often lies in the details. This indicates the overall problem of dividing the total development resources between the platform development and product development.

One of our goals of this project is to capture the complexities of gaming with a visual, on-time representation of their decisions. One approach is the use of mind maps and portfolio techniques. A framework becomes more valuable, both to academia and practitioners, when it can be measured. Through some sort of a measurement tool, a consensus can be achieved and data misinterpretations minimized. There are many ways to quantify theoretical frameworks such as with econometrics, statistics, mathematical modelling, to name a few.

Here, we apply portfolio techniques (where product development projects are evaluated in relation to other projects) to capture the complexity of product platforms. How a platform is planned and configured, in terms of the technology composition contained in the sub-systems and respective interfaces linking these sub-systems, has a significant impact on the trade-offs between the degree of standardization and customization of product families and respective end products. The portfolio management approach can provide the following benefits (MIKKOLA, 2001):

a) systematic analysis of projects;

b) relative strengths and weaknesses of projects to be revealed;

c) consensus among different functions; 
d) evaluation with respect to business level performances; and

e) clear gaps and future development opportunities to be highlighted.

This method is chosen because the platform management should be evaluated in terms of the firm's resources and how they are aligned with other platforms, as shown in Figure 6.

The Platform Portfolio Matrix (PPM) measures the degrees of modularity embedded in a given product architecture (y-axis) with respect to the degree of the platform alignment with other platforms (x-axis). The bubbles indicate the amount of resources used. The following key factors define the degree of modularity $[M(u)]$ with respect to the number of unique components $[\mathrm{u}]$ embedded in a given product architecture: components $[\mathrm{N}$ and $\mathrm{u}]$, degree of coupling $[\delta]$, and substitutability factor [s] (Equation 1) refer to Mikkola (2006) for the derivation and application of $\mathrm{M}(\mathrm{u})$.

$$
\mathrm{M}(\mathrm{u})=\mathrm{e}^{-\mathrm{u}^{2} / 2 \mathrm{~N} \delta}
$$

$\mathrm{M}(\mathrm{u})$ considers the decomposition and nature of product architecture (which can vary from integral to modular) with respect to component composition (i.e. types of components classified according to degree of customization and standardization) and interfaces. The degree of platform alignment takes into consideration various performance criteria for complementary platforms that are necessary for the implementation of the platform under investigation. The PPM is divided into four quadrants:

Quadrant I: this quadrant shows that the platform is not modular and is not quite aligned with other platforms.

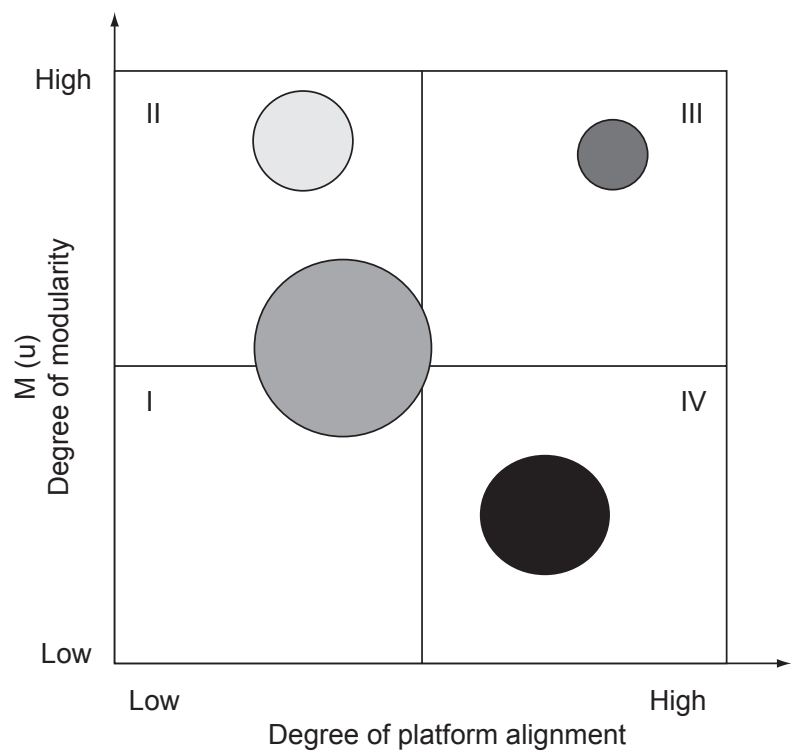

Figure 6. The platform portfolio matrix.
This outcome can be caused by a platform that is integral in nature, that is, in its creation stage where its role (hence alignment) with other platforms is not known.

Quadrant II: this quadrant shows that, the platform is very modular but not aligned with other platforms. This may be caused because the firm had not considered that such platform should be planned for short- and medium-term continuous improvement, which may be the symptoms of companies that have recently embarked on platform thinking.

Quadrant III: this quadrant shows that the platform is very modular and, at the same time, aligned with other platforms. Theoretically, this should be the ideal situation. It also is an indication that there is a great potential for success in the market with a high degree of component sharing across platforms. We suspect, however, that there are very few companies that belong to this quadrant. Platform management requires a multi-task perspective, and most firms are not very good at handling such complexity.

Quadrant IV: this quadrant shows that although the platform is not modular, it is aligned with other platforms. This may be the case of a platform that competes on superior quality and performance as criteria rather than on price. This is typical of platforms based on proprietary knowledge (mostly typical of small to medium size enterprises), in which they are engaged in niche markets.

\section{Conclusion}

This paper presented some preliminary findings of the project on the platform management we are working with LEGO. Based on our on-going research, we have described how games are being used as a way to simulate and play with several scenarios of aligning the various platforms that exist in LEGO. As research on platform management is gaining increasing attention in the academia, we have also proposed how a platform can be captured with the portfolio management thinking. Although beyond the scope of this paper, we are simulating and playing with the Platform Portfolio Matrix with different measurement criteria. Other simulations are also tested. 


\section{Referências bibliográficas}

BECK, J.; WADE, M. Got Game - How the Gamer Generation is Reshaping Business Forever. Harvard: Harvard Business School Press, 2004

CUSUMANO, M. A.; GAWER, A. The elements of platform leadership. MIT. MIT Sloan Management Review, p. 51-58, spring, 2002.

ERENS, F.; VERHULST, K. Architectures for product families. Computers in Industry, 33, no 2-3, 165-178, 1997.

FARRELL, R. S.; SIMPSON, T. W. Product platform design to improve commonality in custom products. Journal of Intelligent Manufacturing, v. 14, n. 6, p. 541-556, 2003.

FORD, H. Today and Tomorrow. Garden City, New York: Doubleday, Tage, and Company, 1926. Cambridge: Massachusetts Productivity Press, 1988.

GUMMESSON, E. Qualitative Methods in Management Research. 2. ed. California, USA, Thousand Oaks: Sage Publications, 2000.

HANSEN, P. H. K.; LARSEN, J. H.; MABOGUNJE, A.; LEIFER, L. Simulating design coordination - The StanfordAalborg Empirical Studies Part (1). In: A. RIITAHUHTA (Ed.). INTERNATIONAL CONFERENCE ON ENGINEERING DESIGN, Proceedings... Tampere, Finland, 1997.

HANSEN, P. K.; MIKKOLA, J. H. Platforms and architectures," NORDDESIGN CONFERENCE, Proceedings..., Tampere, Finland, aug. 18-20, 2004.

KOLB, D. A. Experiential Learning: Experience as the Source of Learning and Development. Englewood Cliffs, New Jersey: Prentice-Hall, Inc., 1984.

KRISHAN, V.; GUPTA, S. Appropriateness and impact of platform-based product development. Management Science, v. 47, n. 1, p. $52-68,2001$.

LEE, H. Postponement for mass customization: Satisfying customer demands for tailor-made products. In: GATTORNA, J. (Ed.). Strategic Supply Chain Alignment: Best Practice in Supply Chain Management. Gower Publishing Limited, Chapter 5, p. 77-91, 1998.

MABOGUNJE, A.; LEIFER, L. J.; LEVITT, R. E.; BAUDIN, C. "ME210-VDT: A managerial framework for improving design process performance. FRONTIERS IN EDUCATION CONFERENCE. Proceedings... Atlanta, Georgia, 1995.

MEYER, M. H.; DALAL, D. Managing platform architectures and manufacturing processes for nonassembled product. Journal of Product Innovation Management, v. 19, n. 1, p. 277-293, 2002.
MEYer, M. H.; LEHnERD, A. H. The Power of Product Platforms. New York: The Free Press, 1997.

MIKKOLA, J. H. Portfolio management of R\&D projects: Implications for innovation management. Technovation, v. 21, n. 7, p. 423-435, 2001.

Capturing the degree of modularity embedded in product

architectures. Journal of Product Innovation Management, v. 23, n. 2, p. 128-146, 2006.

MIKKOLA, J. H.; GASSMANN, O. Managing modularity of product architctures: Toward an integrated theory. IEEE Transactions on Engineering Management, v. 50, n. 2, p. 204-218, 2003.

MIKKOLA, J. H.; HANSEN, P. K. Defining platform templates. INTERNATIONAL PRODUCT DEVELOPMENT CONFERENCE. 12., Proceedings... Copenhagen, Denmark, jun 13-14, p. 1073-1086, 2005.

MIKKOLA, J. H.; SKJØTT-LARSEN, T. Supply-chain integration: Implications for mass customization, modularization, and postponement strategies. Production Planning \& Control, v. 15, n. 4, p. 352-361, 2004.

MUFFATTO, M.; ROVEDA, M. Developing product platforms: Analysis of the development process. Technovation, v. 20, n.11, p. 617-630, 2000.

O'GRADY, P. The Age of Modularity - Using the New World of Modular Products to Revolutionize your Corporation. Adams and Steele Publishers, 1999.

PINE, J. Mass Customization - The New Frontier in Business Competition. Boston, MA: Harvard Business School Press, 1993.

ROBERTSON, D.; ULRICH, K. T. Planning for product platforms. Sloan Management Review, v. 39, n. 4, p. 19-31, summer, 1998.

SCHRAGE, M. Serious Play - How the Best Companies Simulate to Innovate. Harvard Business School Press, 2000.

SCHÖN, D. The Reflective Practitioner. Cambridge, Massachusetts: Basic Books, 1983.

SIMON, H. The Sciences of the Artificial. MIT Press.Mass, 1996.

ULRICH, K. T. The role of product architecture in the manufacturing firm. Research Policy, v. 24, n.3, p. 419-440, 1995.

ULRICH, K. T.; EPPINGER, S. D. Product Design and Development. McGraw-Hill, New York, 2004.

YIN, R. K. Case Study Research - Design and Methods. 2. ed. Thousand Oaks, CA: Sage Publications, 1994

\section{Sobre os autores}

\section{Juliana Hsuan}

Copenhagen Business School, Department of Operations Management, Solbjerg Plads 3, DK-2000 Frederiksberg, Denmark, e-mail: jh.om@cbs.dk

\section{Poul Kyvsgaard Hansen}

Aalborg University, Center for Industrial Production, Fibigerstraede 16, DK-9220 Aalborg Oest, Denmark, e-mail: kyvs@iprod.auc.dk 
